\title{
Enhancing the Quality of Research in Europe: Theoretical Perspectives on and Guiding Principles for Researcher Development
}

\author{
Linda Evans
}

\section{Introduction}

The observation that: 'Europe does not perform particularly well in terms of truly outstanding research' (European Commission Directorate General for Research 2005 , p. 2) was the impetus behind the creation not only of the European Research Area (ERA) and, linked to this, the European higher education research area (EHEA), but also the European Research Council and its funding policy. Set in motion by the Bologna Process, the whole point of these initiatives is to transform Europe into a cohesive, world class powerhouse of the 21 st century global knowledge economy. As observed by Maria Helena Nazaré, President of the European University Association:

\footnotetext{
Europe needs well-trained researchers to meet the challenges that we are facing. In a time of crisis, it is essential that European universities have the capacity to train new researchers who can think innovatively and creatively; researchers who will form an essential element of overcoming our common challenges through new ideas and intellectual leadership (Byrne et al. 2013, p. 6).
}

A key objective is to rival the research 'super power' status and output enjoyed by the United States, along with more recently developed research-focused nations, notably China and India (European Commission 2007).

Perceived as a crucial link between the EHEA and the ERA, doctoral education is identified as the cornerstone upon which will be built Europe's future world class research excellence, and since 2003 it has been a key feature within the remit of the Bologna Process. Along with early career research training more generally, it was reprioritised at the Bergen and London ministerial conferences in 2005 and 2007 respectively, while the European University Association (EUA) convened a semi-

\footnotetext{
L. Evans $(\bowtie)$

University of Leeds, Leeds, UK

e-mail: 1.evans@education.leeds.ac.uk

(C) The Author(s) 2015

A. Curaj et al. (eds.), The European Higher Education Area,

DOI 10.1007/978-3-319-20877-0_37
} 
nar in Salzburg in 2005 for the purpose of discussing doctoral programmes within the Bologna process. In 2008 the EUA established a Council for Doctoral Education with the remit of contributing to the development, advancement and improvement of doctoral education and research training in Europe. More recently, a set of Principles for Innovative Doctoral Training, defined with the help of experts from university associations, industry and funding organisations, was endorsed by the Council in Brussels in November 2011.

The first of these principles reads:

Striving for excellent research is fundamental to all doctoral education and from this all other elements flow. Academic standards set via peer review procedures and research environments representing a critical mass are required. The new academic generation should be trained to become creative, critical and autonomous intellectual risk takers, pushing the boundaries of frontier research (European Commission Directorate General for Research \& Innovation 2011).

Yet there is something of a mismatch between the aspirations and vision expressed in this statement and consideration of how European doctoral education may be developed, for the remaining six principles largely ignore issues related to the quality of doctoral research. Indeed, the European Commission Directorate General for Research \& Innovation (2011) emphasises that principle 7, quality assurance, 'is not about the quality assurance of the $\mathrm{PhD}$ itself'.

This paper focuses on that evident mismatch. Innovative doctoral training, I observe below, cannot be defined narrowly. With its focus on structures and systems, the Bologna discourse overlooks the vital issue of how we may directly enhance the quality of researchers and, by extension, of research. I argue that the quality of European research is crucial to raising its profile and ensuring that the ERA becomes a serious contender within the highly competitive international research community. Our best chances of ensuring that 'the new academic generation may be trained to become creative, critical and autonomous intellectual risk takers, pushing the boundaries of frontier research' (European Commission Directorate General for Research \& Innovation 2011) lies in understanding how researchers develop, and applying that understanding to specific policy initiatives. Drawing upon my own research-informed theoretical perspectives, I propose a researcher development model aimed at improving the quality of European research, by enhancing the professionalism of future generations of European researchers. I begin by outlining what we know about researcher development.

\subsection{Understanding Researcher Development}

Researcher development is an embryonic field of research and scholarship. Whilst there is certainly a growing research-informed body of literature relating to research and researchers, and the interaction between the two (e.g. Akerlind 2008; Coleridge et al. 2004; Drnach 2002; Fairweather 2002; Fox 1992; Fox and Mohapatra 2007; 
Hemming et al. 2007; Manathunga et al. 2007; McGrail et al. 2006; Rath 2009; Wimsatt et al. 2009), we know relatively little about how researchers (particularly academics as researchers) conduct their work and what attitudes they hold towards it, and about the nature of their development and the process(es) whereby it occurs. Moreover, research emanating from Europe, and relating to European contexts, is under-represented. Notwithstanding the valuable contributions to the knowledge base made by some Europeans (e.g. Abramo et al. 2009; Deem and Lucas 2007; Gordon 2005; Rees et al. 2007; Vekkaila et al. 2012), the bulk of the literature seems to be supplied by American and Australasian authors.

Tight (2008, p. 596) identifies higher education research, as 'a developing field of study', which 'could be conceived of as a partially explored territory through which a variety of tribes traverse'. We may think of the narrower, more recently emerged and hence more 'developing', researcher development as one such tribeor, to be more precise, the territory of the 'tribe' of researchers for whom it represents a shared interest. Conceptually, it remains unchartered terrain, for the question of what is meant by 'researcher development' has scarcely been scrutinised in a scholarly manner; there is an acute shortage of proposed definitions of researcher development from which to draw consensus or debate differences. Having found no explicit stipulative definition, I have formulated my own conceptual analysis of researcher development (presented in Evans 2011a, 2012, 2014a). Outlining its key elements below, I draw upon my conceptualisation in presenting my argument for how the European research community may better prepare, support and develop its early career-and indeed, experiencedresearchers to become, in the words of the European Commission Directorate General for Research \& Innovation (2011): 'creative, critical and autonomous intellectual risk takers, pushing the boundaries of frontier research'.

\subsubsection{Conceptualising Researcher Development}

I define researcher development very broadly and succinctly, as: the process whereby people's capacity and willingness to carry out the research components of their work or studies may be considered to be enhanced, with a degree of permanence that exceeds transitoriness (Evans 2012). The words 'may be considered to be' are intended to convey my interpretation of any form of development as subjectively determined, in accordance with different needs, interests and agendas; what a university's strategic management team, for example, may consider to be researcher development may be quite different from interpretations of it held by individual academics, or academic development professionals.

My use of the word 'people' rather than 'researchers' is intended to convey inclusiveness: researcher development is not only about making researchers better at researching, it is also about transforming into researchers people representing other constituencies. I choose the word 'capacity' rather than alternatives such as 'skills', 'knowledge', 'attitudes', 'understanding', 'competence' or 'procedures' not only because it encompasses all of these — and more (McIntyre and McIntyre 1999)—but 
also because it implies the incorporation of consideration of externally-imposed or externally-derived factors, such as resources or academic freedom or (professional) status, whose improvement or enhancement contributes to defining the contextual dimension of researcher development. My reference to people's 'willingness' to undertake research is perhaps superfluous, given that I interpret capacity as including this, but I include it explicitly to factor in the importance of motivation and attitudinal preparedness.

Researcher development constitutes a specific form of professional developmentit involves people's development of the research-related elements of their professionalism and professional lives. It is therefore a sub-category of professional development, so to understand it we need to understand professional development, or human development, more broadly. The complex ecologies of people's lives are becoming increasingly recognised as the fusion of work and personal life; development that occurs in a professional or work context, and that enhances one's capacity to undertake one's work, must inevitably impinge upon or influence the attitudes, viewpoints, knowledge, understanding, and skills that may be applied to one's life as a whole, and vice versa: a point that is implicitly incorporated into Eraut's (2004) thesis on workplace learning. My conceptualisation of researcher development-my understanding of what it is - incorporates this more holistic interpretation of development. Yet, ironically, in order to reveal its component parts, I illustrate this holism through deconstruction.

\section{Deconstructing Researcher Development: A Conceptual Model}

My conceptualisation is illustrated in Fig. 1, as a model of my interpretation of the componential structure of researcher development. Essentially it represents a basic deconstruction of researcher development into three main components or elements: behavioural development, attitudinal development and intellectual development. I define each of these as, respectively: the process whereby people's behaviour or performance are modified; the process whereby people's attitudes are modified; and the process whereby people's knowledge, understanding or reflective or comprehensive capacity or competence are modified. I emphasise that each is

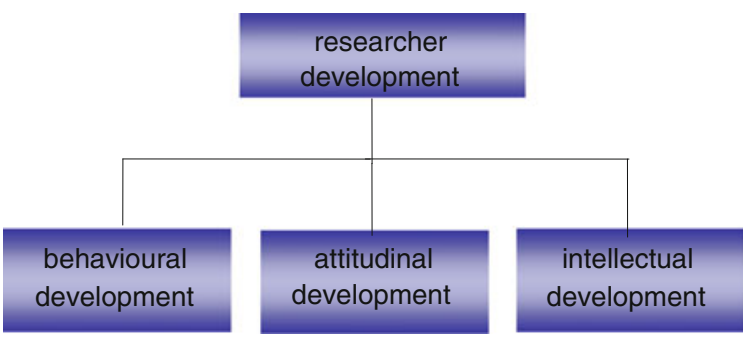

Fig. 1 The componential structure of researcher development: 1st tier components 
intended to be located under (or subsumed within) my overarching 'umbrella' definition of researcher development, presented above, and therefore must comply with the conditions implied by it. This means that the term 'modified' should be understood as ameliorative modification - change for the better, which constitutes what may be considered the enhancement of researcher capacity. It also means that the modificatory activity referred to in the three subsidiary definitions must be specifically research-capacity-enhancement-focussed.

The behaviour- or performance-modification that constitutes the behavioural component (see Fig. 1) of researcher development refers to the full range of physical activity that forms part of what may be categorised as research activity or performance. This component is about 'doing' research, in all its forms, and at all of its stages. It includes both independent and interpersonal activity. Attitudinal development and intellectual development, in contrast, involve mental activity.

To better explain each of these three components I identify their components, of which I currently identify eleven, in total. These may be thought of as being foci of change, or change dimensions. How these foci of change-these sub-components, or second tier dimensions - relate to the three 'first level' or 'first tier' components is illustrated in Fig. 2. My labels for the second tier components are intended to be generic labels rather than narrowly stipulative. Their vertically-sequenced arrangement is necessitated by space restrictions and does not imply any hierarchical positioning.

Processual change (see Fig. 2) is about change in relation to the processes that constitute people's research practice-how they 'do' or 'go about' the various elements of research-related activity. It is likely to account for a large proportion of

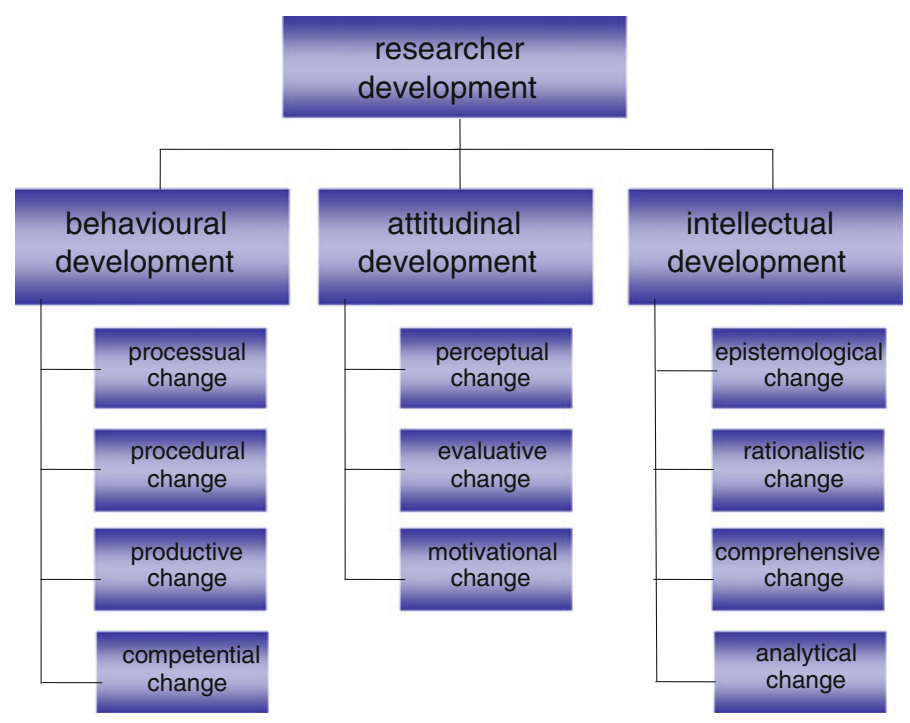

Fig. 2 The componential structure of researcher development: 1st and 2nd tier components 
research-related activity, which may be described using rather generic labels (e.g. networking and collegial interaction, writing, reading, speaking, data collection, data display, data reduction) or labels that are, to varying degrees, more specific and that represent more-and different-micro levels of description or categorisation (e.g. testing, observing, comparing, contrasting). Procedural change relates to changes to people's capacity to deal with or manage procedures within research-related practice. Often such procedures will be imposed at institutional level or within the wider discipline - such as research bids' applications procedures. Sometimes they may be self-imposed strategic procedures. Competential change involves the increase or enhancement of research-related skills and competences, such as the development or refinement of writing, analytical or presentation skills. Productive change refers to change to people's research output: to how much they achieve, produce or 'do', such as an increase in published output or research grant applications or increased involvement in conferences, seminars and research networks.

Perceptual change refers to change in relation to people's perceptions, viewpoints, beliefs and mindsets-views about whether, for example, research should have relevance and usefulness and impact upon policy and practice: whether it should be 'applied' or 'pure'; or about whether it may - and should — be done by inexperienced and untrained amateurs/practitioners. Perceptual change relates, too, to perceptions of research as a component of one's work, or a constituent of one's professional identity; as such it incorporates self-perception. Drawing upon the etymological derivative of the word 'evaluation', by evaluative change I do not mean people's capacity to evaluate, as a research process; rather, the term refers to changes to people's research-related values, including not only 'grand' values (such as equality and social justice), but also the day-to-day minutiae of what they consider important: that is, what matters to them, and what they like about, research and researching. Motivational change refers to increases in people's motivation and levels of morale and (job) satisfaction in relation to their research activity.

By epistemological change I mean change to the bases of what people know or understand in relation to research and researching, and to their research-related knowledge structures, as well as the theoretical and conceptual frameworks within which they locate and undertake their research activity. Rationalistic change is about change to the extent of, and the nature of, the reasoning that people apply to their research practice. Analytical change refers not specifically to data analysis (which is a research process and therefore falls within the processual dimension), but to change to the degree or nature of the analyticism applied to research-related activity. Finally, comprehensive change involves the enhancement or increase of people's research-related knowledge and understanding.

Deconstructed in this way, we see researcher development as a multi-dimensional process or agency, for its constituent parts-its dimensionsbecome much more apparent. Knowing and understanding the complex ways in which these may fuse together and interact to effect the process whereby people develop as or into researchers is - or ought to be-invaluable to those responsible for promoting this process. We may in fact conceptualise researcher development as 
the enhancement of researchers' professionalism (just as professional development more broadly may be thought of as the enhancement of people's professionalism Evans 2014b). Researcher professionalism would then be represented as having the same basic componential structure as researcher development, for it is change (for the better) in relation to one or more of its components or dimensions that constitutes researcher development. Researcher professionalism may accordingly be represented as in Fig. 3. This representation differs from that in Fig. 2 only in relation to subtle distinctions in the labels used: researcher professionalism is deconstructed into 'components' and 'dimensions' and researcher development into 'development' and 'change'.

It is important to emphasise - as I demonstrate elsewhere, with examples (Evans 2011a, 2012) - that what constitutes researcher development is not dependent upon change in relation to all of the eleven identified dimensions of researcher professionalism shown in Fig. 3. Yet whilst it is conceivable that some identifiable 'units' of individuals' development as or into researchers may involve change in relation to only one dimension, most are likely to involve the interaction of multiple dimensions. Developing European researchers into 'creative, critical and autonomous intellectual risk takers' who are inclined to push 'the boundaries of frontier research' - to repeat once again the vision articulated by the European Commission Directorate General for Research \& Innovation (2011) - may, for example, first involve changing a researcher's perceptions of what constitutes frontier research, which may then lead to a change in relation to her or his values, as s/he begins to appreciate the merits of undertaking such research, despite its risks. This may then lead to changes in relation to her/his motivation to undertake such research and,

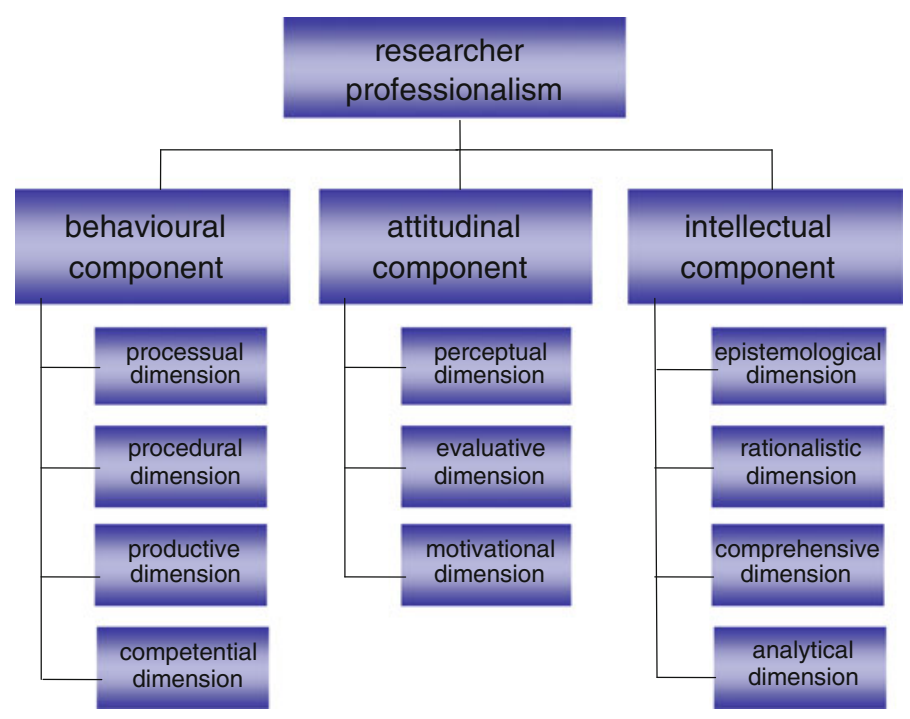

Fig. 3 The componential structure of researcher professionalism 
motivated to embrace such changes to her or his research practice, s/he may increase her or his knowledge and understanding of what such research involves, which may then lead to her/his enhancing his or her research skills, as a result of which s/he is able to change the processes within her or his research practice, and/or the epistemological basis of her/his research. This hypothetical example illustrates the kinds of sequences of change in relation to the dimensions of researcher development that typically occur in each individual 'developee', whereby, as a kind of chain reaction, change in relation to one dimension may kick-start change in relation to another, and then another, and then another, and so on. I do not imply that the example presented above - of perceptual change leading to evaluative change, which then leads to motivational change, which leads to comprehensive change, which leads to competential change, which leads to processual and/or epistemological change-represents the most commonly-occurring change sequence; I simply present it as a heuristic illustration of the multi-dimensionality of researcher development, as indicated in the model (Fig. 2).

My model may be challenged by those who contest the specific form it takes, or whose conceptualisations of researcher development are not aligned with mine. I welcome such criticism and potential divergence; I neither seek nor advocate unanimity, for it is through dialogue and debate that we will enhance our understanding of researcher development and how it occurs, and augment the researcher development-related knowledge base, which, by extension, will advance the field. Such knowledge and understanding should inform the agenda, and any frameworks underpinning programmes, for the education and training of European doctoraland other early career - researchers. Yet in the absence of critiques or challenges to my work, or of competing conceptual models, I locate my argument below within the framework delineated by my own conceptualisation of researcher development and its implications for developing European researchers. I outline those implications in the next section.

\section{Training the "New Academic Generation": Implications of Understanding Researcher Development and How It Occurs}

Incorporating consideration of this conceptualisation of researcher development, how then should we tackle the development of European researchers in alignment with the 'striving for excellent research' agenda that promotes 'creative, critical and autonomous' risk-taking in 'pushing the boundaries of frontier research' (European Commission Directorate General for Research \& Innovation 2011)?

We should tackle it not simply and solely by formulating guiding principles to which the European research community is expected to sign up, for whilst they represent a laudable attempt to promote European research excellence, the Principles for Innovative Doctoral Training are too vague and general to impact 
meaningfully on research quality. Their emphasis on the form and structure of doctoral programmes and development provision for doctoral students, at the expense of consideration of what makes for excellent, frontier research, and how early career researchers may be encouraged to pursue it, represents a short-sighted and somewhat unambitious strategy that reflects simplistic and inadequate understanding of how research cultures are enhanced and strengthened and how researchers develop. Byrne et al. (2013, p. 25) remind us that '[t]he goal of doctoral education is to bring the doctoral candidate from the level of a talented Master's student capable of understanding and reproducing knowledge to a researcher capable of producing knowledge independently'. This kind of development will not be assured simply by agreed structures, procedures and guiding principles.

A key point that I reiterate throughout this paper is that researcher development is multidimensional. As such, it is shot through with complexity, represented by the countless permutations of sequences of dimensions of change that constitute single 'episodes' of individuals' development. A researcher's development throughout her or his entire career is made up of countless such 'episodes', which are generally experienced unconsciously, as fleeting moments that merge and coalesce to the extent of becoming imperceptible. Ask a researcher to recall and trace the stages of her development, and her response will focus on broad-brush, easily identifiableand quantifiable - events, milestones or achievements; she may observe that she is much better at designing questionnaires than she once was, or better at formulating research questions, and that she has increased her annual output of journal articles. But she is most unlikely - without being prompted and questioned - to identify the minute perceptual, cognitive, rationalistic or competential changes that, collectively and cumulatively, formed the bases of and precipitated the multiple development episodes that, collectively and cumulatively, constituted the development that she is able to recognise in herself.

Yet, irrespective of whether they recognise my specific ideas or accept every detail of my model, those who have an interest in, or are responsible for developing, researchers need to understand something of the process that I call the 'micro-level development' cognitive process of professional — or, more specifically, researcherdevelopment: 'what occurs inside an individual's head in order for her/him to experience a single professional development "episode"” (Evans 2014b, p. 183); '[b] y "micro-level" professional development I mean the individual, singular "episodes" that constitute, as far as they are discernible, the unitary components of "bigger picture", or wider scale, professional development' (Evans 2014b, p. 186). I have identified as a key element of this micro-level development process the individual's - the developee's-recognition of something as a 'better way' of 'doing' things (applying a broad interpretation of 'doing' to include mental as well as physical activity). What I mean by 'better' is: better than what preceded, and than what is superseded by, the newly-accepted and adopted practice: in the context of this paper, research-related practice. By my definition, this represents the manifestation of professional development (Evans 2014b) or, more specifically, researcher development (Evans 2012). Whilst this recognition on the part of the 'developee' of a 'better way' is essential if attitudinal or intellectual change is to occur, behavioural 
change is possible to impose upon people, without their recognising it as a 'better way'. Such imposition is evident, for example, in many aspects of academic working life in research-intensive universities in developed countries, such as where neoliberal policies create pressure on academics to relentlessly pursue research funding. Whilst they may disapprove of such institutional policies, academics may comply with them to the extent of changing their behaviour by applying for more grants. Based on my definition of it, this behavioural change (representing productive change - see Fig. 2) is likely to be categorised by university senior management as researcher development. Yet for those academics who do not recognise increased activity on funding applications as a 'better way', it would be categorised not as development, but as deleterious to their research-related practice. So, whilst strategic compliance may represent changed practice that may be considered by some stakeholders to represent change for the better - and hence development - it does not represent the most effective researcher development. The latter (effective researcher development) occurs when hearts and minds are won over, and the 'developee', recognising it as potentially a 'better way' for her or him, buys into an initiative. The most effective policies for developing the European researcherincluding training initiatives - will therefore be those that s/he is likely to buy into.

\subsection{Promoting Recognition of a 'Better Way'}

How may those charged with, or responsible for, developing them encourage or promote amongst researchers recognition that something represents a 'better way'? Such recognition relates to various different levels and dimensions of researchers' consciousness, for 'better' is a relative descriptor; it may feasibly address any or all of a range of issues that relate to, inter alia, processes, choices and standards in doing research and that address, respectively, researchers' how?, which? and to what level?-focused questions (Evans 2014a).

First, developing as a researcher includes acquiring knowledge and understanding of how things operate in the world of research, and how to 'do' researchincluding specific processes, such as grant application writing, research design and method, analysis, writing for publication, and becoming acculturated within the disciplinary research community. Illustrating the importance in the researcher development process of recognising what represents a 'better way', and applying this recognition to increasing one's competence as a researcher, is a quote from an interviewee in one of my recent research projects. ${ }^{1}$ He reminisces on how, in his earliest days as a junior researcher, he had been supported and mentored by a professor:

\footnotetext{
${ }^{1}$ The project, Leading professors: professorial academic leadership as it is perceived by 'the led' was funded by the UK's Leadership Foundation for Higher Education and was carried out 20122013. Its preliminary findings are presented in Evans et al. (2013).
} 
He [the professorial colleague] taught me to write. ...The first thing I ever wrote for him, he came into my room when I'd finished the first draft and - I'm exaggerating when I say, 'He threw it at me'; he didn't - but he gave it me back and said, 'When are you going to learn to write about one thing?' And I was a bit disappointed about that.

...And when he took it away and gave it back to me - rewritten - I could see why. It was so much better. I mean, I just had to accept this was so much better than what I did. And I guess for, maybe six months, he slowly - I mean, I guess, basically, I improved - but he slowly did less and less in terms of redrafting my stuff, until, after a year or so, he never touched it; he just left it to me (Evans 2014a, pp. 51-52, emphasis added).

Second, an important aspect of development as a researcher involves making choices about a wide range of issues and tasks, such as: which funders to apply to; which calls for tender to pursue and which to let go; which journals to submit to; which conferences to attend; whom to network with; which tasks to prioritise and which to place on the back-burner. Some choices will obviously represent a 'better way' than others for the researcher, as is evident in the comments of an early career academic (an interviewee in one of my research projects (see footnote 1)) who regretted making the choices he had made in relation to what writing projects to focus on, and recognised retrospectively what, for him, might have been better choices or decisions:

I've found that, as a junior lecturer, I've been offered things that for various reasons I thought I should say 'Yes' to... and that they've probably spread me a bit more thinly than I would've liked to have been. I could probably have said, 'No' to a few articles and chapters...and ended up with four really strong items for the $\mathrm{REF}^{2}$ (Evans 2014a, p. 53).

Third, in order to determine what, for them, constitutes 'better' research practice, researchers need to know to what level they ought to be working; they need to know what is considered good, and what is considered unsatisfactory practice. A standards or quality yardstick is therefore necessary. This yardstick may take many forms, but its key feature or property is that it illustrates a standard against which individuals may judge their own performance; it facilitates the kind of comparison and introspection that prompts one researcher to contemplate or consider the quality of his or her own research output and recognise that there is room for improvement. Nicolin et al. (2015) illustrate how junior physicists (doctoral students), working alongside senior academics within the interdisciplinary and international European research community within CERN, become acculturated into academic life and, learning what expectations prevail, and what kinds and volume of scientific output constitute the norm, become productive themselves. The CERN community constitutes one

\footnotetext{
${ }^{2}$ This is a reference to the UK's research Excellence Framework (REF), which is the nationally applied mechanism for allocating government funding to higher educational institutions based upon the quality of their research activity. It occurs every few (5-7) years. For each of a range of subjects in which it engages in research, each university is invited to submit as a key part of its REF entry a profile of research output represented by academics' selected publications (up to four per academic). The quality of this output is judged by peer review subject panels.
} 
form of yardstick for those working within it, but a yardstick may also take the form of knowledge and experience of the norms and standards that prevail in research communities or cultures that are unfamiliar, representing a stark contrast to the cultures within which one has spent one's formative years. An early career Slovak researcher, for example, describes his exposure to such a 'new' (to him) culture during a prolonged visit to the USA - 'My time in the USA was in many respects an eye-opener for me' (Beňuš 2015) - and, drawing upon his observations and experiences in a different continent, is able to discern weaknesses in, and to critique, the research and academic cultures and communities in his native Slovakia.

Intellectual or academic leadership may also serve as a yardstick; individuals manifesting such leadership will often be professors and other senior academics and luminaries (Evans 2013, 2014a; Macfarlane 2012) whose work is considered to exemplify high quality research and scholarship. But a yardstick may also be more explicit, taking the form of clearly expressed standards of research performance and researcher professionalism to aim for (rather like professional standards used in other contexts, such as those applied to teachers in England Evans 2011b). It is the latter that I propose as a framework for researcher development in Europe.

\section{A "Better Way" for the European Researcher: A Framework for Career-Long Development}

'The new academic generation' (European Commission Directorate General for Research \& Innovation 2011) in Europe needs to be aware of the kinds of standards that they should be striving for in relation to the different dimensions of their research activity. On its own, a common agreed set of principles underpinning, and structures aimed at ensuring consistency in, doctoral education across Europe will not generate such awareness. To return to the example of early career academic, Štefan Beňuš, despite such structures and principles being in place in his native Slovakia, without a yardstick against which he was able to evaluate the Slovak system and environment, he would have been much less aware of what he now identifies as their weaknesses and much less equipped to fashion his own development as an academic and researcher in line with internationally recognised standards of good research. He writes (Beňuš 2015):

According to the Academic Ranking and Rating Agency of Slovakia (ARRA), there were 6144 doctoral students (or early career researchers) registered at state universities funded by public funds, but their output is weak, which is mainly attributed by ARRA to doctoral supervisors' low publication and citation outputs

... . Academic identities in Slovakia must inevitably reflect the weak research cultures that prevail and that yield unimpressively low research by the standards of many other European and Anglo-Saxon research communities ... prioritisation of research and academics' research identities go hand-in-hand; where the first is low, the second is likely to be weak. 
... The goalposts that help define the nature of academic work, by indicating direction and focus, are unclearly visible to those academics in Slovak who want to participate in the kinds of activities that academics in other European countries perform with skill and understanding of what is required to succeed. Without such direction and focus, academic identities remain confused and unclear, and their development and expansion are stifled.

As is implied by Beňuš's (2015) perspective, if we are to achieve more consistent development of early career researchers across Europe, and to encourage and promote their 'striving for excellent research' (European Commission Directorate General for Research \& Innovation 2011) and their production of pioneering research, doctoral supervisors - those academics with whom early career researchers interact, who are responsible for guiding and mentoring them, and whose standards of scholarship they are most likely to emulate - need to be aware of, or be capable of achieving, what the rest of the developed world considers good research. There is a need then to indicate clearly to European researchers - not only to the next generation, but also to those responsible for developing this generation - these 'goalposts' to which Beňuš (2015) refers. It is therefore on these that we should be focusing, by working towards agreeing and delineating the features of excellent research and, by extension, the characteristics and qualities of excellent European researchers. In the next section I show how this may be approached.

\subsection{Delineating the Characteristics of Excellent European Researchers: 'Extended' and 'Restricted' Professionality}

In the 1970s Eric Hoyle published his heuristic models of what he identified as two categories of English schoolteachers: 'restricted' and 'extended' professionals (Hoyle 1975) - terms that have endured through the work of several researchers, along with the basic perception underpinning them: that professional or practitioner groups are heterogeneous in relation to the professionalism they manifest and the quality of their practice. Much of my work has been influenced by Hoyle; I have adapted, extended and applied his models to my work on teacher morale and job satisfaction (Evans 1997, 1998) and professional development, and to my more recent work on researcher development (Evans 2009, 2010, 2013). I draw upon them here to indicate how the European academic community may develop yardsticks against which researchers of all levels of seniority and experience - not only early career researchers-may measure their own achievements and progress towards excellence.

\subsubsection{The 'Extended' European Researcher}

What defines 'excellent research'? What are the characteristics of researchers who are likely to excel: to go on to become 'creative, critical and autonomous intellectual risk takers, pushing the boundaries of frontier research' (European 
Commission Directorate General for Research \& Innovation 2011)? What does such a person 'look like', professionally, academically and intellectually? Adopting Hoyle's (1975) terminology, I have labelled such a person the 'extended' professional or the 'extended' researcher (Evans 2009, 2010, 2013). Such a researcher working within the social sciences, I have argued, would typically, inter alia:

- conduct highly rigorous research;

- draw upon basic and advanced research skills;

- strive constantly to develop and extend her/his methodological competence;

- adapt established research methods and develop methodology;

- generate and develop theory from research findings;

- perceive research methodology as a field of study in itself;

- strive constantly to apply deep levels of analysis to research data;

- recognise the value of, and utilise, comparative analysis, meta-analysis, synthesis, replication, etc.;

- constantly reflect upon, and frequently revisit and refine, his/her own studies;

- have developed the skill of effective criticism and apply this to the formulation of his/her own arguments;

- publish frequently in 'high ranking', peer reviewed academic journals;

- disseminate ground-breaking theoretical issues and contribute to, and take a lead in developing, discourse on theory;

- recognise the applicability to a range of contexts (including, in particular work contexts) of generic skills developed within and alongside research activity.

Expressed in this form, as a list of typical indicators of what may be considered excellent or exemplary practice (in which respect it parallels the typical form, used in Anglo-Saxon contexts, of presentation of professional standards for specific workforces, such as teaching, e.g. AITSL 2011; DfES 2004; Scottish Executive 2005; Welsh Government 2011), this model of the 'extended' researcher may serve as an aspirational guide and, by extension, as a potential motivator, for researchers at any stage of their careers.

I do not propose this precise model, with the specific researcher characteristics or 'standards' listed above, as the one that the European research community should adopt; rather, I present it as indicative of the kind of yardstick of researcher excellence that could be formulated and promoted. The detail of the content must be discussed and agreed, so that as many stakeholders as possible will have ownership of it. This could be done at European level, with the aim of agreeing a model of the characteristics of excellent European researchers generally, or it could be specific to disciplines, or to national contexts, or even to institutions. Yet it is also important to present developing researchers with both ends of the yardstick against which they should be evaluating their own practice, indicating not only standards of practice that are considered to represent, but also those considered to fall far short of, excellence. The latter help elucidate the former and encourage introspection on the part of the researcher. 
After Hoyle (1975), I therefore present two models, in order to counterbalance an indicative model of the 'extended' European researcher with one of the 'restricted' European researcher (see Fig. 4). It is important to emphasise that the models should be thought of as two extremes of a continuum, rather than as detached and dichotomised, 'either-or', categories. The characteristics are intended to be indicative, rather than exhaustive, lists of what I identify elsewhere as the three components of professionalism and, by extension, of professional development (Evans 2011b) and, more specifically, of researcher development (Evans 2011a). They indicate the behaviour, attitudes and intellectual capacity that any research community (e.g.

\section{The researcher located at the 'restricted' extreme of the professionality continuum typically:}

conducts research that lacks rigour;

draws upon basic research skills;

fails to develop or extend her/his methodological competence;

utilises only established research methods;

fails to develop basic research findings;

perceives research methods as tools and methodology as a task-directed, utilitarian process;

applies low level analysis to research data;

perceives individual research studies as independent and free-standing;

perceives individual research studies as finite and complete;

struggles to criticise literature and others' research effectively;

publishes mainly in 'lower grade' academic journals and in professional journals/magazines; is associated mainly with research findings that fall into the 'tips for practitioners' category of output;

perceives research activity as separate and detached from wider contexts requiring interpersonal, organisational and cognitive skills.

\section{The researcher located at the 'extended' extreme of the professionality continuum typically:}

conducts highly rigorous research;

draws upon basic and advanced research skills;

strives constantly to develop and extend her/his methodological competence;

adapts established research methods and develops methodology;

generates and develops theory from research findings;

perceives research methodology as a field of study in itself;

strives constantly to apply deep levels of analysis to research data;

recognises the value of, and utilises, comparative analysis, meta-analysis, synthesis, replication, etc.;

constantly reflects upon, and frequently revisits and refines, his/her own studies;

has developed the skill of effective criticism and applies this to the formulation of his/her own arguments;

publishes frequently in 'high ranking' academic journals;

disseminates ground-breaking theoretical issues and contributes to, and takes a lead in developing, discourse on theory;

recognises the applicability to a range of contexts (including, in particular work contexts) of generic skills developed within and alongside research activity.

Fig. 4 Indicative characteristics illustrating the extremes of the 'restricted'-'extended' professionality continuum in relation to research 
disciplinary; institutional) may reasonably be expected to manifest. Members of that community will inevitably be spread widely along the length of the continuum. It would be reasonable to expect - with some exceptions - distinguished professors to be located towards the 'extended' end and early career researchers/academics to tend to cluster around the 'restricted' end. Yet the characteristics are intended to represent and reflect individuals' stances and attitudes towards research(ing), rather than simply knowledge that correlates with length of experience or career status, so early career researchers may feasibly be located towards the 'extended' end of the continuum — particularly in relation to attitudinal and intellectual characteristics - while many veteran researchers may remain relatively 'restricted' throughout their careers.

Implicitly echoing my concern that structures and systems alone will not make for enhanced research quality, Byrne et al. (2013, p. 13) argue that 'universities should support quality culture rather than simply develop quality assurance processes'. My argument in this paper underpins and reflects my support for the development of a very specific form of quality culture: a research-focused developmentalist culture. Such a culture within the European research community would militate against inertia or complacency. It would incorporate recognition of the fact that developing as or into an excellent researcher involves continually and relentlessly progressing, in relation to as many characteristics as possible-however these may be defined or expressed - towards the 'extended' end of the continuum. This may occur unconsciously, through what Eraut (2004) calls 'implicit' (workplace) learning. It may also be instigated deliberately, as researchers recognise and accept that where they currently find themselves on the 'restricted'-'extended' continuum does not represent the best they can strive for in terms of achieving their full potential, so they take steps to rectify that. Such is the awareness that a developmentalist research culture in Europe would foster: that all European researchers have development needs throughout the entire length of their careers. Our best chance of promoting and achieving what the European Commission Directorate General for Research \& Innovation (2011) calls 'excellent' and 'frontier' research is to foster such a culture within and across the ERA and the EHEA and to acculturate early career researchers into it.

As I imply above, the specific characteristics that constitute the models of 'restricted' and 'extended' educational researchers shown in Fig. 4 are not set in stone; they may be formulated with a particular European research community in mind-tailored to match specific needs or goals - and revised to correlate with current contextual demands. Above all, an explicit model of the 'extended' educational researcher, defined by an agreed set of characteristics and disseminated widely, has the capacity both to present the European research community with an articulated vision of what is currently perceived as researcher excellence- thus signalling the 'right' direction with which it should align itself — and, in doing so, to motivate researchers of all career stages to embrace developmentalism, and embed it within their mindsets, to the extent that it becomes part and parcel of their practice. 
Providing the 'unity in diversity' that Bitusikova (2009, p. 23) calls for, such models of 'extended' and 'restricted' researcher professionality could easily serve as a common European model for doctoral education that is truly developmental - a model that is aimed at unifying provision and standards by the application of a common delineation of quality that would be the focus of researcher development. It would help combat problems, such as those identified by Beňuš (2015) above, and those identified by Krasniewski (2008) of a dilution of the quality of doctoral study applicants in Poland resulting from rapid expansion of higher education, and, in particular, of doctoral programmes. The analyticism and reflectivity that the models promote are intrinsically development-focused, whilst being directed towards improving quality and raising standards. Yet the generic nature of the research-related skills and competences intended to be developed transcends specific epistemological and methodological traditions, stances and allegiances. 'Extended' professionality is primarily quality-related, rather than substantively-determined.

Only by developing and promoting a yardstick for researcher excellence will Europe have any chance of success in enhancing the quality of its research and in its attempts 'to harness more of the world's best minds to motor the European economy' (Robertson 2008, p. 10). Only by such a focus on research quality will we foster a European community of 'researchers who can think innovatively and creatively; researchers who will form an essential element of overcoming our common challenges through new ideas and intellectual leadership' (Maria Helena Nazaré, cited in Byrne et al. 2013, p. 6) and of researchers who are 'creative, critical and autonomous intellectual risk takers, pushing the boundaries of frontier research' (European Commission Directorate General for Research \& Innovation 2011).

Open Access This chapter is distributed under the terms of the Creative Commons Attribution Noncommercial License, which permits any noncommercial use, distribution, and reproduction in any medium, provided the original author(s) and source are credited.

\section{References}

Abramo, G., D'Angelo, C. A., \& Di Costa, F. (2009). Research collaboration and productivity: Is there correlation? Higher Education, 57, 155-171.

AITSL, Australian Institute for Teaching and School Leadership. (2011). Australian professional standards for principals. Canberra: Ministerial Council for Education.

Åkerlind, G. (2008). Growing and developing as a university researcher. Higher Education, 55, 241-254.

Beňuš, Š. (2015). Academic identity in Slovakia: A personal comparative view. In L. Evans \& J. Nixon (Eds.), Academic identities in higher education: The changing European landscape (pp. 99-114). London: Bloomsbury.

Bitusikova, A. (2009). Reforming doctoral education in Europe. Academe, 95(1), 21-23.

Byrne, J., Jørgensen, T., \& Loukkola, T. (2013). Quality assurance in doctoral education-results of the ARDE project. Brussels: European University Association.

Coleridge, S. T., Smith-Barbaro, P., \& Knisley, C. (2004). A practical method for increasing scholarly activity in an academic family medicine department. Teaching and Learning in Medicine, 16(2), 181-185. 
Deem, R., \& Lucas, L. (2007). Research and teaching cultures in two contrasting UK policy contexts: Academic life in education departments in five English and Scottish universities. Higher Education, 54(1), 115-133.

DfES, Department for Education and Skills. (2004). National standards for headteachers: Guidance. London: DfES.

Drnach, M. J. (2002). Designing an incentive plan for researchers. The Journal of Research Administration, 33(1), 13-17.

Eraut, M. (2004). Informal learning in the workplace. Studies in Continuing Education, 26(2), 247-273.

European Commission. (2007). Green paper: The European research area: New perspectives (text with EEA relevance). Brussels: European Commission.

European Commission Directorate General for Research. (2005). Frontier research: The European challenge: High level expert group report executive summary. Brussels: European Commission.

European Commission Directorate General for Research \& Innovation. (2011). Principles for innovative doctoral training. Brussels: European Commission.

Evans, L. (1997). A voice crying in the wilderness? The problems and constraints facing "extended" professionals in the English primary education sector. Teachers and Teaching: Theory and Practice, 3(1), 61-83.

Evans, L. (1998). Teacher morale, job satisfaction and motivation. London: Paul Chapman.

Evans, L. (2009). Developing research capacity in the social sciences: A professionality-based model. International Journal for Researcher Development, 1(2), 134-149.

Evans, L. (2010). Developing the European researcher: "Extended" professionality within the Bologna process. Professional Development in Education, 36(4), 663-677.

Evans, L. (2011a). The scholarship of researcher development: Mapping the terrain and pushing back boundaries. International Journal for Researcher Development, 2(2), 75-98.

Evans, L. (2011b). The "shape" of teacher professionalism in England: Professional standards, performance management, pro-fessional development, and the changes proposed in the 2010 White Paper. British Educational Research Journal, 37(5), 851-870.

Evans, L. (2012). Leadership for researcher development: What research leaders need to know and understand. Educational Management, Administration and Leadership, 40(4), 432-435.

Evans, L. (2013). The professional status of educational research: Professionalism and developmentalism in 21st century work-ing life. British Journal of Educational Studies, 61 (4), 471-490.

Evans, L. (2014a). What is effective research leadership? A research-informed perspective. Higher Education Research and Development, 33(1), 46-58.

Evans, L. (2014b). Leadership for professional development and learning: Enhancing our understanding of how teachers develop. Cambridge Journal of Education, 44(2), 179-198.

Evans, L., Homer, M., \& Rayner, S. (2013). Professors as academic leaders: The perspectives of 'the led'. Educational Management, Administration and Leadership, 41(5), 674-689.

Fairweather, J. S. (2002). The mythologies of faculty productivity: Implications for institutional policy and decision making. The Journal of Higher Education, 73(1), 26-48.

Fox, M. F. (1992). Research, teaching, and publication productivity: Mutuality versus competition in academia. Sociology of Education, 65, 293-305.

Fox, M. F., \& Mohapatra, S. (2007). Social-organizational characteristics of work and publication productivity among academic scientists in doctoral-granting departments. The Journal of Higher Education, 78(5), 542-571.

Gordon, G. (2005). The human dimensions of the research agenda: Supporting the development of researchers throughout the career life cycle. Higher Education Quarterly, 59(1), 40-55.

Hemming, B. C., Rushbrook, P., \& Smith, E. (2007). Academics' views on publishing refereed works: A content analysis. Higher Education, 54, 307-332.

Hoyle, E. (1975). Professionality, professionalism and control in teaching. In V. Houghton, et al. (Eds.), Management in education: The management of organisations and individuals (pp. 314320). London: Ward Lock Educational in association with Open University Press. 
Krasniewski, A. (2008). Transformation of doctoral training in Poland. Higher Education in Europe, 33(1), 125-138.

Macfarlane, B. (2012). Intellectual leadership in higher education: Renewing the role of the university professor. Abingdon: Routledge/SRHE.

Manathunga, C., Lant, P., \& Mellick, G. (2007). Developing professional researchers: Research students' graduate attributes. Studies in Continuing Education, 29(1), 19-36.

McGrail, M. R., Rickard, C. M., \& Jones, R. (2006). Publish or perish: A systematic review of interventions to increase academic publication rates. Higher Education Research and Development, 25(1), 19-35.

McIntyre, D., \& McIntyre, A. (1999). ESRC teaching and learning programme: Capacity for research into teaching and learning-final report.

Nicolin, A., \& Buzatu, F. (2015). The Romanian PhD students at CERN: The Bologna process and beyond.

Rath, J. (2009). A report of a New Zealand-based funding initiative designed to improve a university's research culture. The Journal of Research Administration, 40(1), 90-100.

Rees, G., Baron, S., Boyask, R., \& Taylor, C. (2007). Research-capacity building: Professional learning and the social practices of educational research. British Educational Research Journal, 33(5), 761-779.

Robertson, S. (2008). The Bologna process goes global: A model, market, mobility, brain power or state-building strategy? In An invitational paper to ANPED's Annual Conference. Caxambu, Belo Horizonte, Brazil.

Scottish Executive. (2005). Ambitious, excellent schools: Standard for headship-November 2005. Edinburgh: Scottish Executive.

Tight, M. (2008). Higher education research as tribe, territory and/or community: A co-citation analysis. Higher Education, 55, 593-605.

Vekkaila, J., Pyhälto, K., Hakkarainen, K., Keskinen, J., \& Lonka, K. (2012). Doctoral students' key learning experiences in the natural sciences. International Journal for Researcher Development, 3(2), 154-183.

Welsh Government. (2011). Revised professional standards for education practitioners in Wales: Guidance. Cardiff: Welsh Government, Llywodraeth Cymru.

Wimsatt, L., Trice, A., \& Langley, D. (2009). Faculty perspectives on academic work and administrative burden: Implications for the design of effective support services. The Journal of Research Administration, 40(1), 71-89. 